\title{
Impugnación de resoluciones y disposiciones urbanísticas locales en la Comunidad Valenciana
}

\author{
José M. ${ }^{\text {a }}$ Boquera Oliver \\ Catedrático de la Universidad de Valencia
}

SUMARIO: I. INTRODUCCIÓN. II. NORMAS GENERALES. 1. Competencia de la Jurisdicción Contencioso-administrativa. 2. La legitimación activa. 3. Plazo para ejercitar algunas acciones públicas. III. ALGUNAS CUESTIONES DISCUTIDAS EN LA IMPUGNACIÓN DE LOS PROCEDIMIENTOS DE ELABORACIÓN DE LOS PLANES DE URBANISMO Y PROGRAMAS DE ACTUACIÓN INTEGRADA. 1. Trámites y aprobaciones. 2. Acuerdo de sometimiento a información pública del Plan o Programa de Actuación. 3. La suspensión del otorgamiento de licencias como consecuencia de la información pública de los Planes. 4. Aprobación provisional y definitiva del Plan.

\section{INTRODUCCIÓN}

Del cataclismo que provocó la Sentencia del Tribunal Constitucional de 20 de marzo de 1997 en la legislación estatal del suelo se han salvado algunos preceptos de la Ley de 26 de junio de 1992. La Ley 6/1998, de 13 de abril, sobre régimen del suelo y valoraciones, declara vigentes de aqué1la, entre otros, los artículos 303, 304, 305 y 306, todos ellos del capítulo II del Título IX de la Ley del Suelo de 1992 que tiene por epígrafe «Acciones y recursos». La legislación estatal del suelo contiene, pues, reglas sobre la «impugnación de resoluciones y disposiciones urbanísticas» aplicables en todo el territorio español. Algunas de estas normas son excepciones a los preceptos de la Ley de la Jurisdicción Contenciosoadministrativa y de la Ley de Régimen Jurídico de las Administraciones Públicas y del Procedimiento Administrativo Común y otras son repeticiones o aclaraciones de las disposiciones de estas leyes.

La Ley valenciana Reguladora de la Actividad Urbanística, de 15 de noviembre de 1994, 6/1994, aunque no se ocupa de los recursos, también ha suscitado algunas cuestiones con respecto a la impugnación de resoluciones y disposiciones urbanísticas. En esta ocasión nos ocuparemos de algunas de ellas relacionadas con los recursos en la legislación estatal del suelo aplicable en la Comunidad Valenciana y con repercusión sobre una de sus figuras más características, y de algunas peculiaridades en la impugnación de actos urbanísticos regulados por la Ley valenciana citada. Primero, de los preceptos especiales sobre recursos de la legislación urbanís- 
tica general y, después, de la impugnación de los procedimientos de elaboración de los Planes de Urbanismo y Programas de Actuación Integrada establecidos por la Ley valenciana Reguladora de la Actividad Urbanística.

\section{NORMAS GENERALES}

Las reglas especiales de la Ley del Suelo sobre recursos se refieren a

1. ${ }^{\circ}$ La competencia de la Jurisdicción Contencioso-administrativa;

2. ${ }^{\circ}$ la legitimación activa, y

3. ${ }^{\circ}$ el plazo para ejercitar algunas acciones públicas.

\section{Competencia de la Jurisdicción Contencioso-administrativa}

El orden jurisdiccional contencioso-administrativo es competente, como regla general, para conocer de los recursos contra «la actuación de las Administraciones públicas sujeta al Derecho administrativo» (artículo 1. 1 de la Ley 29/1998), pero también tenemos reglas especiales en los primeros artículos de esta Ley. Entre las materias que la citada Ley incluye de manera explícita en el ámbito de este orden jurisdiccional figuran los contratos administrativos [artículo 2. b)] por no considerarlos actuación sujeta al Derecho administrativo.

La Ley del Suelo de 1992 (artículo 303) dice que «tendrán carácter jurídico administrativo todas las cuestiones que se suscitaren con ocasión o como consecuencia de los actos y convenios regulados en la legislación urbanística aplicable entre los órganos competentes de las Administraciones Públicas y los propietarios individuales o asociados o empresas urbanizadoras, incluso las relativas a cesiones de terrenos para urbanizar o edificar».

Actuación sujeta al Derecho administrativo es, según la Ley de la Jurisdicción de 1998, los actos administrativos, la inactividad de la Administración y las vías de hecho administrativas. Administraciones públicas son las que enumera su artículo $1 .^{\circ} 2$. Pero esta Ley no dice lo que es el Derecho administrativo, sobre el que existen diversas concepciones. El artículo 303 de la Ley del Suelo de 1992 parece querer aclarar esta cuestión para un sector del Ordenamiento jurídico. Nos dice que la legislación urbanística es Derecho administrativo. Creo que esto no es cierto, pues en la legis- 
lación urbanística hay preceptos de diversa naturaleza. Pero sea lo que sea lo que cada uno pensemos sobre el Derecho administrativo, a efectos jurisdiccionales, todo lo regulado por la legislación calificada o de contenido urbanístico aplicable a las Administraciones Públicas en relación con los propietarios o empresas urbanizadoras se considerará de la competencia del orden contencioso-administrativo. No tenemos que buscar razones para poder llegar al orden jurisdiccional contencioso-administrativo cuando se aplique la legislación urbanística: todas las cuestiones que bajo el techo de la legislación urbanística se susciten entre Administraciones públicas y propietarios de terrenos o empresas urbanizadoras se llevarán ante el orden contencioso-administrativo para que las resuelva.

El artículo 303 de la Ley del Suelo de 1992 se refiere a las relaciones entre Administraciones Públicas y los propietarios o empresas urbanizadoras. La legislación valenciana sobre urbanismo, en las actuaciones integradas, que son «la obra pública de urbanización conjunta de dos o más parcelas, realizada de una sola vez o por fases, conforme a una única programación» (artículo 6. 3 de la LRAU), ha colocado entre la Administración municipal y los propietarios al agente urbanizador y tenemos que averiguar qué orden jurisdiccional resolverá los litigios que surjan entre el urbanizador y los propietarios.

El urbanizador es un concesionario de la Administración. El artículo 2.d) de la Ley de la Jurisdicción Contencioso-administrativa dispone que «el orden jurisdiccional contencioso-administrativo conocerá de las cuestiones que se susciten en relación con los actos administrativos de control o fiscalización dictados por la Administración concedente, respecto de los dictados por los concesionarios de los servicios públicos que impliquen el ejercicio de potestades administrativas conferidas a los mismos, ...».

El agente urbanizador, ¿es titular de potestades administrativas? Potestad administrativa es la posibilidad de crear unilateralmente e imponer a otro consecuencias jurídicas que cabe destruir si no se acomodan al Derecho. Esta especie de poder público sólo el Legislador puede conferirla. No puede la Administración otorgarla mediante contrato o de cualquier otra forma. El Legislador la confiere intuitu personae por lo que no es transmisible a otro sujeto.

El urbanizador no recibe del Municipio, al contratar con él, el poder de imponer obligaciones económicas a los propietarios, de sancionarles, de expropiarles u ocupar temporalmente sus terrenos, ... Las Leyes sí pueden conferirle potestades administrativas. En este caso el urbanizador podría dictar actos administrativos que serían recurribles ante la Administración 
municipal y después ser llevados ante el orden jurisdiccional contenciosoadministrativo. El resto de las relaciones jurídicas entre el urbanizador y los propietarios serán jurídico-privadas y de los litigios que de ellas surjan conocerán los jueces del orden jurisdiccional civil.

La Ley valenciana Reguladora de la Actividad Urbanística faculta al urbanizador a repercutir «el coste de las inversiones, instalaciones y obras y compensaciones necesarias para ejecutar el Programa» «en la propiedad de los solares resultantes» (artículo 29.7) y esto es una potestad administrativa, una imposición de obligaciones económicas que ahora no calificaremos con mayor precisión ni matizaremos ${ }^{1}$. Contra sus manifestaciones acudiremos a la Jurisdicción Contencioso-administrativa y como, según el artículo 303 de la Ley del Suelo de 1992, todos los convenios o contratos celebrados entre la Administración y los propietarios o empresas urbanizadoras y regulados por la legislación urbanística, son de la competencia de la Jurisdicción Contencioso-administrativa, a ella acudiremos tanto si se trata de una actuación sujeta a Derecho administrativo del urbanizador como de un contrato celebrado por éste y los propietarios. El artículo 2. ${ }^{\circ}$, b) de la Jurisdicción Contencioso-administrativa distingue entre los contratos administrativos y los «demás contratos» sujetos a la Ley de Contratos de las Administraciones Públicas y que ésta califica de privados. De los primeros conoce el orden jurisdiccional contencioso-administrativo y de los segundos, el orden jurisdiccional civil. Pero la Ley del Suelo dispone que todos los litigios surgidos de convenios en los que es parte la Administración pública regulados por la legislación urbanística los resolverá el orden jurisdiccional contencioso-administrativo. Cuando se trate del urbanizador, como su actividad administrativa es controlada por el Municipio y cuando lo sea, se acudirá a la Jurisdicción Contencioso administrativa, según el artículo 2. d) de la Ley de la Jurisdicción. En el ámbito de lo jurídico urbanístico, de conformidad con el artículo 303 de la Ley del Suelo de 1992, si surge

\footnotetext{
${ }^{1}$ El que el urbanizador tenga que acudir al Municipio para que éste ejecute forzosamente las decisiones administrativas que de él proceden no es argumento válido contra la afirmación de que aquél dispone de poder administrativo, pues es sabido que en algunos países muchos actos administrativos procedentes de las Administraciones públicas no son éstas quienes los ejecutan sino los Jueces. En nuestro Derecho, el artículo 95 de la Ley de Régimen Jurídico de las Administraciones Públicas y del Procedimiento Administrativo Común hace una previsión en el mismo sentido, pues dispone que «las Administraciones públicas,..., podrán proceder, ..., a la ejecución forzosa de los actos administrativos, salvo ... cuando la Constitución o la Ley exijan la intervención de los Tribunales». La creación unilateral e imposición de las consecuencias jurídicas es de esencia en el acto administrativo, pero no lo es su ejecución forzosa por su autora o autor.

Por la misión del urbanizador también será uno de sus poderes decidir la ocupación de las parcelas a edificar, aunque si los propietarios se oponen a ella deberá acudir al Municipio para que éste la haga posible.
} 
un litigio con respecto a un contrato no es necesario plantearse si es administrativo o civil para acudir a la Jurisdicción Contencioso-administrativa. El precepto citado de la Ley del Suelo menciona explícitamente a los contratos de cesión de terrenos para urbanizar o edificar. Esta precisión no era necesaria, pues estas cesiones también las regula la legislación urbanística, pero la Ley ha querido remachar su criterio.

La Ley del Suelo se refiere a «actos y convenios regulados en la legislación urbanística». Actos jurídicos son tanto las resoluciones (actos singulares) como las disposiciones (actos generales). La Ley del Suelo en el término «actos» comprende a los actos singulares y a los generales o disposiciones a diferencia, por ejemplo, de la Ley de la Jurisdicción Contencioso-administrativa que a los actos singulares los califica de actos y a los actos generales los denomina disposiciones [artículos 11. 1. a), 12. 1, 25, entre otros].

Hoy la Ley de la Jurisdicción Contencioso-administrativa utiliza el término «actuación» de la Administración y con él, como hemos recordado, se refiere a actos, inactividad de la Administración y vías de hecho administrativas. La inactividad de la Administración y las vías de hecho en materia de urbanismo también pueden ser impugnadas ante la Jurisdicción Contencioso-administrativa, pues el artículo 303 de la Ley del Suelo no pretende limitar, sino ampliar el ámbito del orden jurisdiccional contencioso-administrativo.

\section{La legitimación activa}

La regla general sobre legitimación para recurrir ante el orden jurisdiccional contencioso-administrativo es la de que el recurrente ostente un derecho o interés legítimo lesionado por la actuación de las Administraciones Públicas (art. 19 de la LJCA) y en vía administrativa podrán interponer recursos «los interesados» (artículo 107. 1 de la Ley 30/1992).

El artículo 304. 1 de la Ley del Suelo cambia esta regla para un sector del Ordenamiento jurídico y dispone que «será pública la acción para exigir ante los órganos administrativos y los Tribunales Contencioso-administrativos la observancia de la legislación urbanística...» Esto significa que cualquiera, sin tener que demostrar que ostenta un derecho o interés legítimo lesionado en relación con actos regulados por la legislación urbanística, puede interponer contra ellos recursos en vía administrativa y contencioso-administrativa. 
Para facilitar la fiscalización de la actuación de la Administración en algunas materias, la legislación dispensa a los recurrentes de demostrar que ostentan un derecho o interés en que se destruya el acto impugnado. A esto se le denomina acción popular. El legislador español estima que el urbanismo es una de esas materias en las que conviene dar facilidades a los administrados para que lleguen hasta los jueces y éstos enjuicien las actuaciones contrarias a la legislación que lo regula. La acción popular constituye una excepción a la regla general. Cuando se exige un interés lesionado para llegar al juez, ¿se restringe el control de la Administración? De contestarse afirmativamente esta pregunta tendríamos que concluir que el artículo 19 de la Ley de la Jurisdicción Contencioso-administrativa es inconstitucional por oponerse al derecho, otorgado por el artículo 24.1 de la Constitución, «a obtener la tutela efectiva de los jueces y tribunales...» y habría que proponer que la acción popular fuera la regla general para acudir ante la Jurisdicción Contencioso-administrativa. Pero el artículo citado de la Constitución dice que la tutela jurisdiccional efectiva lo es en el ejercicio de los «derechos e intereses legítimos» de las personas. Aquella existe, pues, sólo para amparar los derechos e intereses legítimos de las personas. Lo que realmente ocurre es que el recurso contencioso-administrativo tiene como misión tanto la defensa de derechos e intereses legítimos como la defensa de la legalidad, incluso esto último es su fin primordial. Trata de impedir que se incumpla la voluntad del Legislador por la actuación de la Administración. Si la defensa de la legalidad frente a la actividad de la Administración es la misión principal del Juez de lo Contencioso-administrativo poco importa quien promueva su actuación. La cuestión desborda el punto que tratamos ahora.

\section{Plazo para ejercitar algunas acciones públicas}

Regla general: «El plazo para interponer el recurso contencioso-administrativo será de dos meses contados desde el día siguiente al de la publicación de la disposición impugnada o de la notificación o publicación del acto que ponga fin a la vía administrativa, si fuera expreso. Si no lo fuera, el plazo será de seis meses...» (artículo 46 de la LJCA). Pero en ocasiones los administrados no se enteran de la existencia de un acto administrativo por su notificación o publicación, sino por la materialización de sus consecuencias jurídicas e incluso, a veces, aparece en la realidad un hecho que debería ir precedido de un acto administrativo sin que éste haya sido dictado. Cuando cualquiera puede recurrir contra una infracción del Ordenamiento jurídico aumentan muchísimo las posibilidades de que el que desee recurrir no conozca el acto administrativo por su notificación, sino 
por la materialización de sus efectos jurídicos. En este caso el plazo para recurrir comienza a computarse desde el momento en que el recurrente se apercibió de dicha materialización y normalmente hay que estar a lo que al respecto manifieste el que interpone el recurso. Esto es lo que con frecuencia ocurre cuando una persona pretende que se paralice o que se derribe una obra de cuya licencia o falta de licencia no ha tenido noticia en forma, pero que considera ilegal. Para que cualquiera no pueda pretender indefinidamente el derribo de la obra que cree ilegal, el artículo 304. 2 de la Ley del Suelo establece que la acción «motivada por la ejecución de obras que se consideren ilegales, podrá ejercitarse durante la ejecución de las mismas y hasta el transcurso de los plazos establecidos para la adopción de las medidas de protección de la legalidad urbanística». Las medidas de protección de la legalidad urbanística en relación con las obras ilegales son varias. Entre ellas está la orden de demolición. El transcurso del tiempo no legaliza las obras construidas ilegalmente, por lo que, en principio, la orden de derribo se puede adoptar siempre, salvo que la ley o el reglamento fijen un plazo para hacerlo. La acción pública también, en principio, podrá interponerse indefinidamente. Un precepto que pretende ponerle un límite al ejercicio de dicha acción tiene una redacción tan inadecuada que no ha conseguido su objetivo.

\section{ALGUNAS CUESTIONES DISCUTIDAS EN LA IMPUGNACIÓN DE LOS PROCEDIMIENTOS DE ELABORACIÓN DE LOS PLANES DE URBANISMO Y PROGRAMAS DE ACTUACIÓN INTEGRADA}

\section{Trámites y aprobaciones}

Como voy a referirme a trámites y aprobaciones antes de ocuparme de lo enunciado recordaré lo fundamental sobre éstos y éstas.

Los actos administrativos son declaraciones de voluntad. Trámite administrativo es lo que prepara, forma y ejecuta la voluntad de la Administración pública. Al trámite lo define su misión. La misión de preparar, formar o ejecutar la decisión administrativa.

Pudiera pensarse que lo que prepara, forma o ejecuta una declaración de voluntad o decisión es una manifestación de memoria, de conocimiento, de deseo, de juicio, pero nunca manifestación de voluntad. Los trámites y los actos definitivos tendrían, en este caso, una composición psíquica diferente. Habitualmente los trámites son manifestaciones de memoria (certificación de antecedentes), de conocimiento (pruebas de hechos), de 
deseo (peticiones, solicitud de datos), de juicio (informes), que por sí mismas no producen consecuencias jurídicas, pero que sirven, son medios, para conseguir la declaración de voluntad de la que nacen los efectos jurídicos. Sin embargo, no es raro que para adoptar una decisión sea necesario tomar antes otras decisiones que unilateralmente crean e imponen al administrado consecuencias jurídicas. Por ejemplo, el mandato al particular para que presente unos documentos; la orden de suspensión de una actividad hasta que se resuelva el expediente. Éstas son declaraciones de voluntad, actos administrativos, que tienen la misión de preparar otro acto administrativo. Son actos administrativos que en el procedimiento tienen la misión de los trámites, preparar el acto que pone fin al procedimiento, pero con la misma naturaleza psíquica y jurídica del acto que preparan.

Los actos administrativos que por su misión son trámites tienen los elementos o componentes de todos los actos jurídicos (causa o apreciación de los hechos, impulso, forma de exteriorizarse, contenido o efectos jurídicos y fin). Los trámites por misión y esencia - los que no son declaraciones de voluntad - suelen también partir de una apreciación de hechos, pero en lugar de impulso o voluntad tienen como elemento constitutivo un recuerdo, un conocimiento, un deseo o un juicio; también tienen forma de manifestarse, pero carecen de efectos jurídicos, aunque su falta o defectos pueden repercutir sobre la aparente existencia y eficacia de la declaración de voluntad que preparan, y su fin es procurar que nazca acertado y legal el acto administrativo definitivo.

Con respecto a las aprobaciones recordaré una cuestión conceptual aunque parezca terminológica. Es muy frecuente que en un órgano colegiado, después de deliberar sobre una propuesta, su presidente pregunte si la misma se aprueba y si la mayoría contesta que sí, declara que la propuesta queda aprobada. El término aprobación se ha utilizado como sinónimo de decisión, pues lo que se ha adoptado ha sido una decisión sobre lo propuesto. En muchos preceptos legales el término aprobación se emplea como equivalente a acuerdo, a decisión, a declaración de voluntad, a acto administrativo.

Pero el término aprobación tiene otro significado. Existen actos que, no para nacer sino para ser eficaces, necesitan que otro los apruebe. Ocurre como con las bombas. Se construyen para explotar, existen antes de explotar, pero necesitan que algo las toque para que se produzca la explosión, para ser eficaces. Hasta que la aprobación no toca al acto éste no es eficaz; la aprobación es condición de eficacia del acto que la necesita. La eficacia de algunos actos administrativos queda demorada a su aprobación que corresponde a un órgano superior a aquél que los adoptó. Este órgano 
puede ser de la misma entidad autora del acto o de otra Administración pública cuando así lo establecen las leyes.

Recordados estos conceptos pasemos a estudiar la impugnación de algunos trámites de los procedimientos de adopción de Planes y Programas de Actuación urbanísticos regulados por la Ley valenciana Reguladora de la Actividad Urbanística.

\section{Acuerdo de sometimiento a información pública del Plan o Programa de Actuación}

En el procedimiento de preparación o tramitación de los Planes Generales, Especiales y Catálogos de Bienes y Espacios Protegidos destacan, entre múltiples informes, consultas y conciertos, tres actuaciones de la Administración municipal: el acuerdo del sometimiento de sus proyectos a información pública (artículo 38. 2. a de la LRAU), la aprobación provisional (artículo 38. 3 de la LRAU) y la aprobación definitiva (artículo 40 de la misma Ley). En los procedimientos de elaboración de Planes Parciales, Planes de Reforma Interior, Estudios de Detalle y Programas para el desarrollo de Actuaciones integradas con Cédula de Urbanización las actuaciones principales son el sometimiento del proyecto a información pública (artículos 45 y 52 de la LRAU) y la aprobación definitiva (artículo 47.7 de la LRAU). Cuando carecen de Cédula de Urbanización y ésta fuese necesaria, las actuaciones son información pública, aprobación provisional y aprobación definitiva (artículo 47.7 de la LRAU).

Los Planes Generales, Especiales y Catálogos de Bienes y Espacios Protegidos sólo pueden ser preparados por Administraciones públicas. Son siempre, como se decía de acuerdo con las Leyes estatales del Suelo, de iniciativa pública. Las Administraciones públicas encargan a sus técnicos o a empresas especializadas la redacción del proyecto del Plan o Catálogo. Este proyecto es, naturalmente, de quien lo ha encargado y pagado.

Los Planes Parciales, Planes de Reforma Interior, Estudios de Detalle y Programas de Actuación integrada pueden ser de iniciativa pública o de iniciativa privada. Serán de iniciativa privada cuando los particulares son quienes los preparan y los proponen a la Administración municipal.

Si la iniciativa es pública cuando los técnicos creen que han terminado el proyecto que les han pedido lo entregan al Ayuntamiento. En los de iniciativa privada cuando el promotor los considera terminados los presenta en el Ayuntamiento para que éste les dé la oportuna tramitación. Los téc- 
nicos que trabajan por encargo del Municipio suelen hacerlo de acuerdo con las indicaciones de éste, mientras que los que han recibido el encargo de particulares preparan el proyecto que a estos les interesa. Por eso es frecuente, casi normal, que a los Ayuntamientos les agrade el proyecto de Plan que han preparado sus técnicos y no es raro que no les guste el que le presentan los particulares acomodado a sus intereses.

Si el proyecto de Plan o Programa agrada al Ayuntamiento, envía para su publicación al Diario Oficial de la Generalidad y a un diario no oficial de amplia difusión en la localidad, un anuncio en el que indica que el proyecto de Plan o Programa se encuentra depositado en la casa consistorial para su consulta pública. Pero si no le agrada el Plan o Programa, que para su tramitación le han presentado los particulares, se lo devuelve manifestándoles que no lo acepta o simplemente lo mete en un cajón, cosa esta última que no debe hacer.

El que se encuentre con que le han rechazado su proyecto de Plan o Programa, porque el Municipio así se lo ha manifestado o porque aprecia que el anuncio de información pública no aparece en los diarios, puede desear recurrir contra este rechazo. Recurrir contra el acuerdo de no someterlo a información pública o contra la falta de acuerdo de someterlo a información pública. En la legislación estatal del suelo esta misma cuestión se planteaba como posible recurso contra la llamada aprobación inicial del Plan, que era la primera actuación del procedimiento de elaboración de los Planes. Con la aprobación inicial se manifestaba que el proyecto de Plan era del agrado del Ayuntamiento y con la falta de su aprobación inicial se manifestaba su desagrado. La aprobación inicial antes, en la legislación estatal, y el sometimiento a información pública, ahora, en la legislación valenciana, son la misma cosa, aunque con nombre diferente, y lo que la jurisprudencia y doctrina dijeron sobre aquélla puede aplicarse a ésta. Nos vale para razonar sobre la naturaleza del sometimiento o no del Plan o Programa a información pública.

En ocasiones la jurisprudencia dijo que la aprobación inicial del Plan era un trámite y, por tanto, inimpugnable ${ }^{2}$. Pero otras veces dijo que cuando un particular presenta un Plan y la Administración municipal no lo aprueba y, como consecuencia, no abre el periodo de información pública, muestra su voluntad de no aceptar el proyecto de Plan presentado, lo que es un acto administrativo y, por tanto, cabe su impugnación.

La Sentencia de 18 de noviembre de 1971, Sala 4. ${ }^{\text {a }}$ (A-4813), dice que en los Planes de iniciativa pública la aprobación inicial tiene el específico

${ }^{2}$ Véase la nota 4. 
valor de acto de iniciación del procedimiento de aprobación y los órganos del planeamiento pueden libremente otorgar o no esta previa aprobación, - lo que equivale a decir que la aprobación inicial es un trámite y que existe libertad para aprobar o desaprobar el Plan-, pero que en los planes de iniciativa privada el acto inicial del procedimiento es la presentación del proyecto por los particulares y la aprobación inicial por el Ayuntamiento «tiene el doble sentido... de examen y valoración del proyecto o plan en todos sus aspectos y de asumirlo como propio, integrándolo en el general desarrollo y ejecución del planeamiento» ${ }^{3}$.

La Sentencia citada dice explícitamente que la aprobación inicial cuando se trata de Planes de iniciativa privada no es lo mismo que cuando el Plan es de iniciativa pública. En éste la aprobación inicial es el trámite con el que comienza el procedimiento de elaboración de los Planes. En los Planes de iniciativa privada, el procedimiento lo inicia la presentación por el particular del proyecto a la Administración y su petición de que lo tramite y apruebe definitivamente. La aprobación inicial del Plan es ya el segundo trámite del procedimiento. Todo el razonamiento de la Sentencia de 18 de noviembre de 1971 se encamina a demostrar que cuando la Administración local no aprueba inicialmente el Plan de iniciativa privada rechaza la petición del particular de que apruebe el Plan y cierra la posibilidad de que el proyecto presentado se convierta en Plan, por lo que aquélla (la no aprobación inicial del Plan) puede ser impugnada. Por eso la Sentencia admitió el recurso.

La Sentencia de 31 de enero de 1980 dice que los actos de aprobación inicial no se pueden equiparar a los «de puro trámite limitados a ordenar la incoación de un expediente» ${ }^{4}$. La aprobación inicial valora el Plan y dice «me gusta»o «no me gusta»; es, pues, una calificación del proyecto de Plan, es un juicio, una declaración de juicio, sobre el mismo. Como algunos consideran que las manifestaciones de juicio de la Administración son actos administrativos, la aprobación inicial sería, pues, para los que esto creen, un acto administrativo y, por tanto impugnable. A mí me pare-

\footnotetext{
${ }^{3}$ La Sentencia añade que en el momento de la aprobación inicial y en el de la provisional las Corporaciones locales no pueden reprobar el proyecto de Plan de iniciativa privada. Solamente pueden introducir modificaciones y demorar el acuerdo hasta que ello se realice o se subsanen faltas iniciales de requisitos o documentos, pero con la obligación general de proseguir la tramitación hasta la aprobación definitiva. Finalmente la sentencia admite el recurso contra la denegación de la aprobación inicial del Plan de iniciativa privada.

${ }^{4}$ Esta Sentencia manifiesta que «el hecho de que no falten declaraciones jurisprudenciales, como las contenidas en las sentencias de 17 de abril de 1975 y 27 de octubre de 1977, calificadoras de acto de trámite al de aprobación inicial de los Planes» de iniciativa privada se debe al deseo de reservar al acto de aprobación definitiva los efectos verdaderamente resolutorios del procedimiento».
} 
ce que la manifestación de juicio no es un acto administrativo, pues los actos administrativos son una especie de acto jurídico y el acto jurídico es una declaración de voluntad que produce consecuencias jurídicas. La declaración de juicio por sí sola no produce efectos jurídicos. ${ }^{5}$

El Ayuntamiento, después de apreciar que no le gusta el Plan (el hecho) sometido a su consideración, puede devolvérselo a quienes se lo han entregado manifestándoles que no lo quiere someter a información pública o simplemente puede guardarlo en un armario. Una cosa y otra son una declaración de voluntad, la primera expresa y la segunda tácita, que rechaza la petición de que el proyecto de Plan se convierta en Plan. Lo primero, la devolución del proyecto de Plan, es un acto expreso, aunque no se diga explícitamente que no se quiere convertirlo en Plan. Lo segundo, no someterlo a información pública, implica denegar la petición; será, pues, un acto tácito. Los actos administrativos sean expresos o tácitos son siempre, por naturaleza, impugnables ${ }^{6}$. La Sentencia del Tribunal Supremo de 31 de enero de 1980 admite el recurso contra la denegación de la aprobación inicial y resuelve sobre el fondo.

La jurisprudencia buscó por diversos caminos admitir la impugnación de la desaprobación inicial de los Planes de iniciativa privada.

Pero aunque la desaprobación inicial y ahora en la legislación valenciana el no sometimiento a información pública de los Planes o Programas, por su situación en los procedimientos de elaboración, fueran calificados de trámite también procedería la admisión de su impugnación, porque los trámites, según dispone el artículo 25 de la LJCA, son recurribles cuando «deciden directa o indirectamente el fondo del asunto, determinan la imposibilidad de continuar el procedimiento, producen indefensión o perjuicio irreparable a derechos o intereses legítimos». El trámite puede ser impugnado cuando realmente se convierte en decisión (declaración de voluntad), al decidir directa o indirectamente el fondo del asunto, lo que también ocurre cuando imposibilita continuar el procedimiento. Cuando el Municipio no envía el anuncio de información pública al Diario oficial imposibilita la continuación del procedimiento.

\footnotetext{
${ }^{5}$ El juicio o valoración de los hechos es sólo la causa del acto administrativo y ésta puede exteriorizarse antes de la declaración de voluntad o con la declaración de voluntad.

${ }^{6}$ A veces el Ayuntamiento rechaza el Plan o Programa de actuación porque lo considera ilegal o contrario a Planes superiores. Éste es el supuesto de la Sentencia de 31 de enero de 1980. El rechazo es consecuencia de un juicio jurídico, no estético o técnico, sino de un juicio sobre la legalidad del Plan o Programa. Este rechazo se tratará igual que el debido a razones estéticas o técnicas por lo que vale para estos supuestos todo lo que acabamos de decir.
} 
La conducta lógica de los Ayuntamientos cuando no les guste el proyecto de Plan o Programa o los consideren contrarios a las leyes o planes superiores, será manifestar que no les gusta, o que lo consideran ilegal, pero que, a pesar de ello, envían el anuncio de información pública al Diario oficial de la Generalidad y a un diario no oficial. Cuando llegue el momento de la resolución del expediente, la aprobación definitiva, podrán, si procede, denegarla o, si sólo deben aprobarlo provisionalmente, propondrán lo que estimen oportuno a quien le corresponda aprobarlo definitivamente ${ }^{7}$. Los términos de la Ley estatal del Suelo dificultaban esta solución. Resultaba un contrasentido no aprobar inicialmente el proyecto de Plan y abrir información pública sobre el mismo. Quizá por esto la Ley valenciana Reguladora de la Actividad Urbanística prescindió de la expresión aprobación inicial y, en su lugar, dispuso que el órgano competente de la Administración lo someterá a información pública, pero se ha entendido que también puede no someterlo a información pública y esto, en este caso, no es una deducción lógica.

Lo que hemos dicho con respecto a la información pública de Planes y Programas y su posible impugnación, es también aplicable a las alternativas técnicas a los Programas que puede presentar cualquier persona y para los que, a través del Alcalde, puede solicitar el sometimiento a información pública (artículo 45. 1 de la LRAU). El Alcalde podrá proponer al Ayuntamiento-Pleno que desestime la petición del particular de abrir la información pública (artículo 45. 2 de la LRAU). El Alcalde y el Ayuntamiento, pueden, según la Ley, actuar así, pero no deben hacerlo. Contra la desestimación de la petición del particular cabrán, por lo dicho, los recursos procedentes.

\section{La suspensión del otorgamiento de licencias como consecuencia de la información pública de los Planes}

«La resolución por la que se convoca el periodo de información pública de los Planes — dispone el artículo 57. 1. b) de la LRAU— surtirá el efecto suspensivo de licencias que la ley estatal asocia a la aprobación inicial de ellos, ...». Es decir, la convocatoria de la información pública da lugar a lo que se ha llamado la suspensión automática del otorgamiento de licencias. Los perjudicados con la suspensión del otorgamiento de las

\footnotetext{
${ }^{7}$ Sobre la aprobación definitiva del planeamiento urbanístico puede verse A. FernÁndEZ CARBALLAL, El urbanismo finalista. A propósito del principio de menor restricción en el derecho de propiedad, Civitas, Madrid, 2002, pp. 201 y ss.
} 
licencias pueden considerarla ilegal y desear llegar hasta los jueces para que éstos la anulen. Esto último también ha suscitado algún problema.

La suspensión automática (sin voluntad de la Administración) de las licencias es consecuencia de lo dispuesto por la Ley; esta suspensión la ha anudado la ley al trámite o hecho de la convocatoria de la información pública; la suspensión es voluntad de la ley. El Ayuntamiento que decide abrir el periodo de información pública es ajeno a la suspensión del otorgamiento de las licencias. Él no ha decidido su suspensión. Incluso puede que no desee suspenderlas.

Contra las leyes no cabe recurso en vía administrativa ni contenciosoadministrativa. Contra los trámites sin las consecuencias que antes hemos visto (artículo 25 de la LJA) tampoco y el anunciar una información pública es un trámite. Entonces, ¿cómo articular el recurso contra la suspensión automática del otorgamiento de licencias?

Los que quieren impugnar la suspensión de las licencias no pueden argumentar que la convocatoria de información pública ha rechazado esto o aquello. Este trámite no decide directa o indirectamente el fondo de nada, ni impide la continuación del procedimiento. Simplemente por él se hace efectiva la voluntad de la ley. Los trámites que hacen efectiva la voluntad de la ley no tienen un tratamiento especial en la Ley de la Jurisdicción Contencioso-administrativa.

El trámite de la convocatoria de información pública del Plan puede haberse adoptado defectuosamente, pues, como toda actuación municipal, está sujeto a un procedimiento: inclusión en la convocatoria y en el orden del día de la sesión a celebrar, constitución del órgano que la adopta, adopción del acuerdo con el quórum necesario, formalización en un acta. Si todo esto no se acomoda a las prescripciones legales y reglamentarias, el trámite de la convocatoria de información pública estará viciado de ilegalidad. Incluso puede que sea jurídicamente inexistente. Por ejemplo, la falta de quórum en la adopción del acuerdo hará que éste sea inexistente, aunque aparente, por la falta de la voluntad requerida.

Contra la Ley nada podemos intentar en vía administrativa o contencioso-administrativa. Únicamente destruyendo el trámite de apertura de la información pública o su apariencia, se podrá evitar la suspensión de las licencias que la Ley impone. Pero los trámites solo son impugnables si se transforman en decisiones o tienen las consecuencias que enumera el artículo 25. 1 de la LJCA. Como en este caso el trámite no decide directa o indirectamente el fondo del asunto, ni imposibilita continuar el procedi- 
miento, sólo si convencemos al juez de que el trámite causa «perjuicio irreparable a derechos o intereses legítimos» (artículo 25. 1 in fine de la LJCA) admitirá el recurso. Esto resultará difícil, aunque no imposible, porque el otorgamiento de las licencias se suspende para impedir que se hagan obras que obstaculicen la ejecución del Plan que se va a elaborar y éste es un interés público al que se subordinan los derechos e intereses particulares. Si no hubiera «resolución por la que se convoca el periodo de información pública» — resolución es el término que utiliza la Ley Reguladora de la Actividad Urbanística, aunque nos parece inexacto, pues no es una resolución propiamente dicha o acto administrativo singular - no se suspenderá el otorgamiento de las licencias, pues la Ley ordena la suspensión de las licencias sólo cuando existe el trámite de sometimiento a información pública del proyecto de Plan. Declarada su inexistencia, eliminada la causa de la suspensión del otorgamiento de licencias, éstas podrán otorgarse. Pero la declaración de inexistencia de la convocatoria de información pública corresponde al Juez de lo Contencioso-administrativo que debe admitir siempre el recurso cuando se alega que realmente no existe lo que parece que existe. Habrá que alegar, pues, no que el trámite está viciado sino que no existe. Pero es difícil que muchos jueces acepten el argumento de que cuando se aportan indicios de que el trámite no existe ni siquiera debe averiguarse si existen causas de inadmisibilidad del recurso contencioso-administrativo, pues se impugna una apariencia con consecuencias jurídicas.

Conozco una decisión del Tribunal Supremo en la que parece se abre camino al argumento que acabo de exponer. La Sentencia de 5 de mayo de 1980 decidió que, aunque normalmente, primero hay que averiguar si el acto es impugnable o no, por lo que ahora nos interesa, si es definitivo o de trámite, y después decidir sobre su legalidad o ilegalidad, cuando se alega la nulidad de pleno derecho, cambia, excepcionalmente, el orden del conocimiento de las cuestiones y, primero, hay que decidir si lo que se examina tiene o no un vicio de nulidad de pleno derecho (ilegalidad o legalidad) y después si es o no es impugnable. El Tribunal Supremo en esta Sentencia aprecia que en la aprobación inicial de la revisión del Plan comarcal de ordenación urbana de Barcelona no hubo nulidad de pleno derecho y después averigua la naturaleza de lo impugnado y, como concluye que la aprobación inicial es un trámite, declara inadmisible el recurso.

Nuestras leyes contienen una relación de causas de nulidad de pleno derecho de los actos administrativos, pero ningún criterio sobre la inexistencia de los mismos. Incluso algunos casos de inexistencia de actos jurídicos, como, por ejemplo, el contenido imposible, figuran como causas de 
nulidad. Por este motivo los Jueces aprecian como de nulidad de pleno derecho casos de inexistencia de actos administrativos. Eso creo que ocurre en la Sentencia citada.

No me parece que cuando se acusa a un acto o a un trámite de nulo de pleno derecho se pueda cambiar el orden del conocimiento de las cuestiones y resolver sobre el fondo del asunto antes que sobre la existencia de un presupuesto del proceso porque, nulo o no, existe acto y los actos son objeto del recurso contencioso-administrativo, pero, cuando se ofrecen indicios de que lo que parece acto no lo es, la actitud del Juez debe ser otra: la de proceder a averiguar sin más si aquello que produce efectos jurídicos es una apariencia, algo carente de existencia para el Derecho.

Si la Sentencia de 5 de mayo de 1980 hubiera estimado que la aprobación inicial era nula de pleno derecho por incompetencia manifiesta, que era el vicio que se alegaba, hubiera admitido y resuelto el recurso contra un trámite inimpugnable, lo que era contrario al artículo 37. 1 de la Ley de la Jurisdicción Contencioso-administrativa de 1956 y ahora sería contrario al artículo 25. 1 de la vigente Ley de la misma Jurisdicción.

Pero si cuando se acusa a una actuación de la Administración de nula de pleno derecho la jurisprudencia admite que se puede decidir sobre este motivo de impugnación antes de averiguar si lo impugnado es un acto o un trámite impugnable, con más razón se podrá actuar así cuando se acuse al acto o al trámite de inexistente. En este caso el Juez de lo contenciosoadministrativo deja de actuar como un juez y se convierte en un debelador de apariencias fantasmales al margen de la Ley ordenadora de la Jurisdicción a la que pertenece.

Si se acusa al acto o al trámite de inexistente debe admitirse y resolverse el recurso sin tener en cuenta ninguna otra cosa, pues no se subvierte el ordenamiento procesal pensado para juzgar actos y trámites impugnables, sino que se juzga la existencia de un efecto jurídico sin nada que sea su origen. La sentencia sólo decidirá si lo impugnado es una apariencia o una realidad. Cuando se impugne un acto o un trámite impugnable la falta del cumplimiento de algún presupuesto procesal siempre debe implicar la inadmisión del recurso.

El acto jurídico puede tener vicios de nulidad, pero la apariencia de acto no, porque no es acto. No debe aplicarse a la inexistencia del acto el régimen de la nulidad de los actos administrativo ni tratar a los actos nulos como si fueran actos inexistentes. 
El camino que propongo para oponerse a la suspensión automática de las licencias es estrecho y, por tanto, difícil el caminar por él, pero creo que es el que debe intentarse seguir.

\section{Aprobación provisional y definitiva del Plan}

El artículo 38. 3 de la Ley Reguladora de la Actividad Urbanística dispone que «el Ayuntamiento-Pleno u órgano competente que promueva o supervise la redacción del Plan (General, Especial o Catálogo de Bienes o Espacios protegidos) resolverá sobre su aprobación provisional, con introducción de las rectificaciones que estime oportunas, y podrá remitirlo a la Consellería competente en Urbanismo interesando su aprobación definitiva».

Con anterioridad a esta Ley valenciana y en relación con la legislación estatal del suelo, se planteó la cuestión de si la aprobación provisional del Plan era un trámite del procedimiento de su elaboración o era un acto administrativo al que la aprobación definitiva le daba únicamente eficacia.

Los que defendieron la tesis de que la aprobación provisional era un trámite decían que con ella el Municipio proponía el Plan, pero lo decidía quien lo aprobaba definitivamente y éste podía aceptar, rechazar o modificar la propuesta municipal.

Los que estimaban que la aprobación provisional, pese a su nombre, era un acto definitivo consideraban que con ella nacía el Plan que carecía de eficacia hasta que no era aprobado definitivamente.

Esta cuestión técnico-jurídica afloraba una importante cuestión política: la de si el Municipio era el planificador de su territorio, o si se lo planificaba el Estado y más tarde la Comunidad Autónoma, cuestión estrechamente relacionada con la autonomía local ${ }^{8}$.

La legislación valenciana ha reducido sensiblemente los casos en los que la Comunidad Autónoma interviene en la aprobación de los Planes, pero aun en los casos (Planes Generales, Especiales y Catálogos) en los que a ésta le corresponde la aprobación definitiva ha alterado sensiblemente la naturaleza de la aprobación provisional y consiguientemente de

\footnotetext{
${ }^{8}$ Pueden verse, C. Escuin Palop, Aprobación definitiva de los planes de urbanismo por las Comunidades Autónomas, Generalitat Valenciana, 1991; I. SEVILla MERINo, «Doctrina y jurisprudencia sobre aprobación de los planes urbanísticos municipales», Revista General de Derecho, núm. 600, 1994, pp. 9547-9576, y «La Responsabilidad Patrimonial de la Administración por la aprobación de Planes Urbanísticos Municipales», Publicaciones FVMP, n. ${ }^{\circ}$ 14, Valencia, 1994.
} 
la aprobación definitiva. El artículo 40. 2 de la Ley Reguladora de la Actividad Urbanística dispone que «las resoluciones autonómicas sobre la aprobación definitiva nunca cuestionarán la interpretación del interés público local formulada por el Municipio desde la representatividad que le confiere su legitimación democrática...» Aumenta, por este lado, la autonomía local pero, por otro lado, en el caso de los Planes Generales, la rebaja, pues impone como «preceptivo el concierto (del Municipio) con la Consellería competente en Urbanismo para definir un modelo territorial municipal acorde con su contexto supramunicipal y con los Planes de Acción Territorial aplicables» (artículo 38. 1, párrafo segundo). El modelo territorial municipal contendrá la interpretación del interés público local por los Municipios, pero esta interpretación la harán aquéllos de acuerdo con la Consejería de Obras Públicas, Transporte y Urbanismo. Me ha parecido oportuno advertir esto que no afecta directamente a la naturaleza de la aprobación provisional, pero sí a su contenido.

Lo dispuesto en el artículo 40. 2 de la Ley Reguladora de la Actividad Urbanística cambia sensiblemente la naturaleza de la aprobación provisional según la había configurado la legislación estatal del suelo. El Municipio envía lo aprobado provisionalmente como propuesta de Plan a la Consellería «interesando su aprobación definitiva», pero en lo aprobado provisionalmente hay una parte que no es propuesta sino disposición definitiva: «la interpretación del interés público local formulada por el Municipio». La expresión es vaga y aparatosa. La interpretación municipal del interés público local quedará recogida por determinaciones del Plan. Estas determinaciones no pueden ser objeto de objeciones por quien tiene la competencia para su aprobación definitiva, mientras que las restantes determinaciones sí que pueden ser rechazadas por la Consellería (artículo 40. 1 de la LRAU), aunque fundándose, «exclusivamente, en exigencias de la política urbanística y territorial de la Generalidad, definida por esta Ley (la Ley Reguladora de la Actividad Urbanística) e integrada por los cometidos» de su artículo 40. 1. Pero ¿cómo distinguir las determinaciones que expresan el interés público local interpretado por el Municipio de las determinaciones que no lo expresan? No será nada fácil, habrá discusiones y casi puede asegurarse que se impondrá la voluntad de la Consellería. Igual ocurrirá cuando haya diferencias sobre el rechazo de una determinación por considerarse contraria a las «exigencias de la política urbanística y territorial de la Generalidad».

Esta configuración valenciana de las aprobaciones provisional y definitiva, ¿tiene consecuencias sobre su impugnación? Si las tiene, ¿cuáles son?

Pudiera pensarse que al decidir el Municipio, en la llamada aprobación provisional, el contenido de las normas que recogen su interpretación del 
«interés público local» y que ninguna otra Administración puede alterar, éstas tienen la condición de disposición administrativa definitiva y pueden ser impugnadas. Sin embargo, no pueden serlo antes de ser eficaces y sólo adquirirán eficacia al ser aprobadas definitivamente. Sin eficacia no pueden lesionar derechos o intereses que es lo que legitima para recurrirlas, aunque en materia de urbanismo puede ejercitarse una acción popular.

La aprobación provisional tiene, por tanto, una parte de propuesta de Plan (trámite) y otra de disposición definitiva del Plan. A la primera la aprobación definitiva le da el ser acto jurídico y a la segunda la eficacia. La propuesta puede no ser aceptada, pero la disposición administrativa necesitada de aprobación definitiva tiene que ser necesariamente aprobada. Esto resulta anómalo o si se prefiere singular, porque cuando la ley faculta a alguien para aprobar una cosa le faculta también, aunque no lo diga expresamente, para desaprobarla. La desaprobación está ínsita en la naturaleza de la facultad de aprobación. Pero la ley, como ocurre en el artículo 40. 2 de la Ley Reguladora de la Actividad Urbanística, puede imponer la aprobación al solo efecto de fijar el comienzo de la eficacia de lo decidido y prohibir la desaprobación, lo cual hace inadecuado el nombre de aprobación provisional para todo lo que ocurre cuando un Municipio hace lo que ahora se denomina aprobación provisional del Plan.

Si la Consellería competente no aprueba definitivamente la parte de propuesta de la aprobación provisional, pide al Municipio proponente que cambie su propuesta según las indicaciones que le formula. Caso de aceptarlas, el Municipio hace una nueva propuesta que la Consellería aprueba definitivamente. Pero si no las acepta se queda sin Plan, pues una de sus partes no ha nacido y la otra ha nacido pero no ha comenzado a ser eficaz. Al Municipio no le queda más remedio, si no quiere dar su brazo a torcer, que recurrir ante el orden jurisdiccional contencioso-administrativo acogiéndose a lo dispuesto por el artículo 21. 2 de la Ley de la Jurisdicción Contencioso-administrativa. De conformidad con este precepto, «se entiende por Administración demandada: a) El organismo o corporación autores del acto o disposición fiscalizados, si el resultado de la fiscalización es aprobatorio. b) La que ejerza la fiscalización, si mediante ella no se aprueba íntegramente el acto o disposición». El apartado b) de este precepto no tiene ninguna lógica sustancial, porque el que no aprueba un acto no se convierte en su autor y, por tanto, no debe ser demandado, como responsable y defensor del mismo, pero lo justifica una razón procesal: que el autor del acto desaprobado o cualquier otro interesado pueda pedir y conseguir del Juez que condene a quien ejerce la fiscalización a aprobar el acto que no ha aprobado. 
Cuando quien tiene que aprobar definitivamente el Plan se limita a callar, aplicaremos las normas sobre su aprobación por silencio positivo (artículo 39. 2 de la LRAU) y, si esto no fuera posible, acudiremos al Juez de lo contencioso-administrativo mediante el proceso contra la inactividad de la Administración.

Con la aprobación definitiva de las disposiciones urbanísticas nacen estas o una de sus partes y otras comienzan a ser eficaces. Por ser disposiciones administrativas no pueden ser recurridas en vía administrativa (Artículo 107.3 de la Ley 30/1992), pero pueden serlo en vía contenciosoadministrativa de conformidad con las normas que la Ley 29/1998, de 13 de julio, contiene para regular su impugnación ${ }^{9}$.

\footnotetext{
${ }^{9}$ Puede verse J. M. ${ }^{\text {a }}$ Boquera Oliver, «La impugnación e inaplicación contencioso-administrativa de los reglamentos», Revista de Administración Pública, núm. 149 (1999), pp. 23 a 36.
} 